\title{
National NIF Diagnostic Program Interim Management Plan
}

Warner, $B$

\section{April 25, 2002}

Lawrence

Livermore

National

Laboratory 


\section{DISCLAIMER}

This document was prepared as an account of work sponsored by an agency of the United States Government. Neither the United States Government nor the University of California nor any of their employees, makes any warranty, express or implied, or assumes any legal liability or responsibility for the accuracy, completeness, or usefulness of any information, apparatus, product, or process disclosed, or represents that its use would not infringe privately owned rights. Reference herein to any specific commercial product, process, or service by trade name, trademark, manufacturer, or otherwise, does not necessarily constitute or imply its endorsement, recommendation, or favoring by the United States Government or the University of California. The views and opinions of authors expressed herein do not necessarily state or reflect those of the United States Government or the University of California, and shall not be used for advertising or product endorsement purposes.

This work was performed under the auspices of the U. S. Department of Energy by the University of California, Lawrence Livermore National Laboratory under Contract No. W-7405-Eng-48.

This report has been reproduced directly from the best available copy.

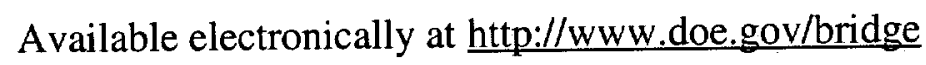

Available for a processing fee to U.S. Department of Energy and its contractors in paper from

U.S. Department of Energy

Office of Scientific and Technical Information

P.O. Box 62

Oak Ridge, TN 37831-0062

Telephone: (865) 576-8401

Facsimile: (865) 576-5728

E-mail: reports@adonis.osti.gov

Available for the sale to the public from

U.S. Department of Commerce

National Technical Information Service

5285 Port Royal Road

Springfield, VA 22161

Telephone: (800) 553-6847

Facsimile: (703) 605-6900

E-mail: orders@ntis.fedworld.gov

Online ordering: http://www.ntis.gov/ordering.htm

OR

Lawrence Livermore National Laboratory

Technical Information Department's Digital Library

http://www.llnl.gov/tid/Library.html 


\section{UCRL ID 148060

\section{National NIF Diagnostic Program Interim Management Plan}

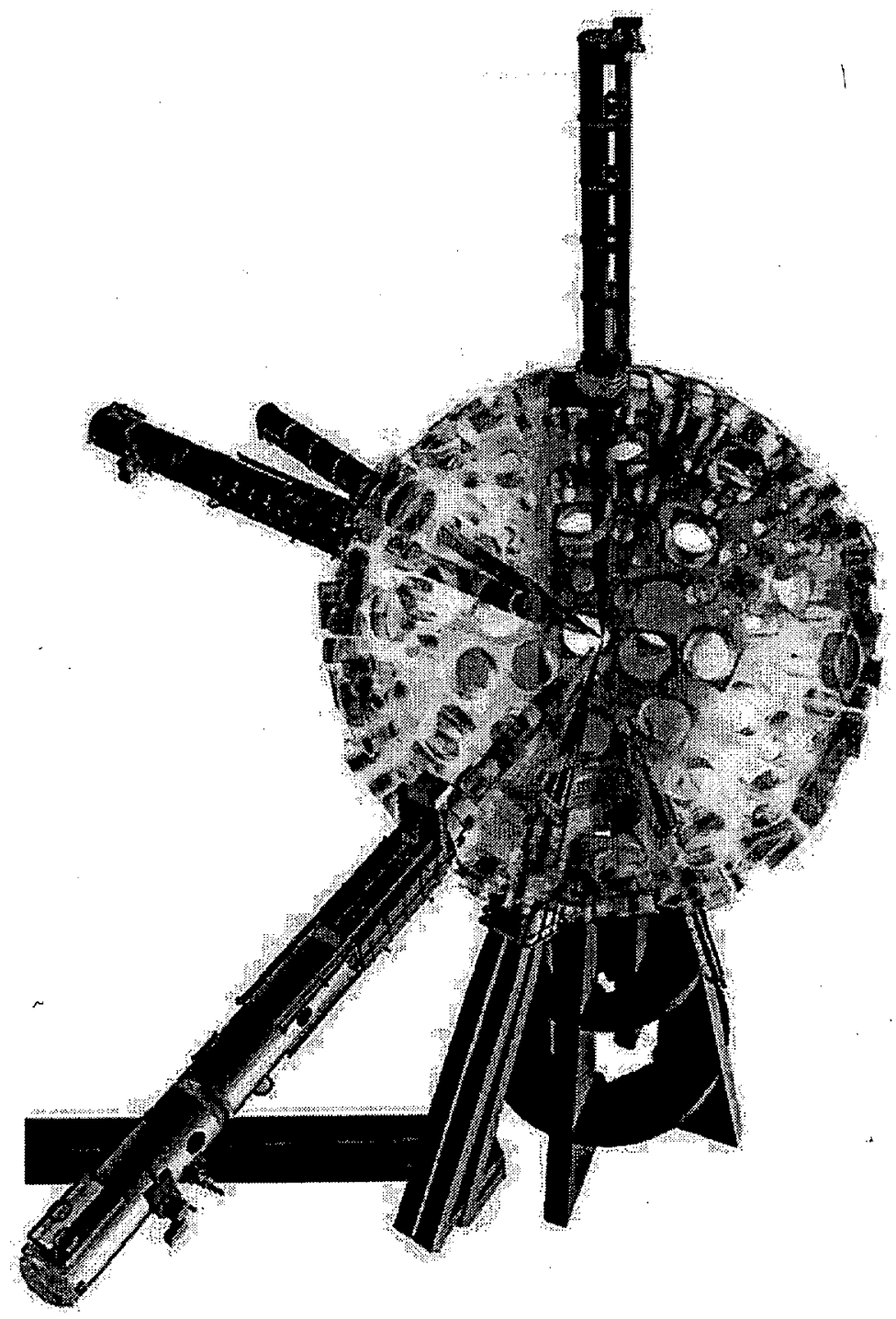

April 2002

Lawrence Livermore National Laboratory 7000 East Avenue Livermore, CA 94550 


\section{DISCLAIMER}

This document was prepared as an account of work sponsored by an agency of the United States Government. Neither the United States Government nor the University of California nor any of their employees, makes any warranty, express or implied, or assumes any legal liability or responsibility for the accuracy, completeness, or usefulness of any information, apparatus, product, or process disclosed, or represents that its use would not infringe privately owned rights. Reference herein to any specific commercial products, process, or service by trade name, trademark, manufacturer, or otherwise, does not necessarily constitute or imply its endorsement, recommendation, or favoring by the United States Government or the University of California. The views and opinions of authors expressed herein do not necessarily state or reflect those of the United States Government or the University of California, and shall not be used for advertising or product endorsement purposes.

This report has been reproduced directly from the best available copy.

Available to DOE and DOE contractors from the

Office of Scientific and Technical Information

P.O. Box 62, Oak Ridge, TN 37831

Prices available from (615) 576-8401, FTS 626-8401

Available to the public from the

National Technical Information Service

U.S. Department of Commerce

5285 Port Royal Rd.,

Springfield, VA 22161

This work was performed under the auspices of the U.S. Department of Energy, National Nuclear Security Administration by University of California Lawrence Livermore National Laboratory under Contract W-7405Eng-48. 


\section{Interim Management Plan for the National NIF Diagnostic}

\section{Program}

Concur:

NNSA Director of Secondaries

and Inertial Fusion Division

NNSA Assistant Deputy Administrator

for Research, Development, and Simulation

Approve:

NIF Director 


\section{TABLE OF CONTENTS}

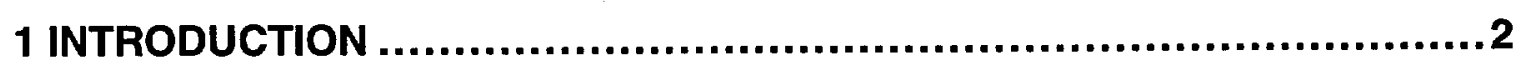

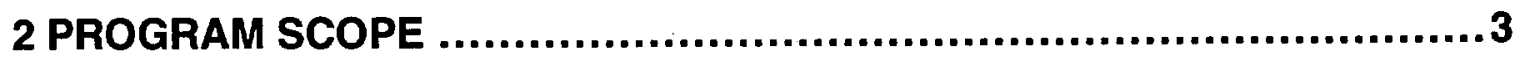

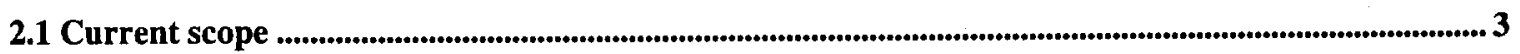

2.2 Criteria for selection of diagnostics as part of scope of NNDP ................................................................... 3

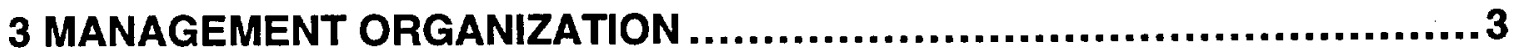

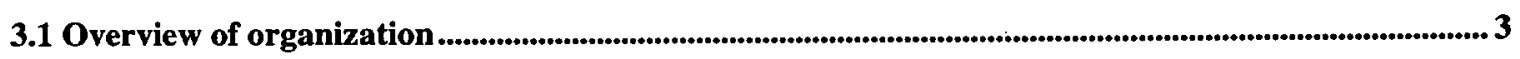

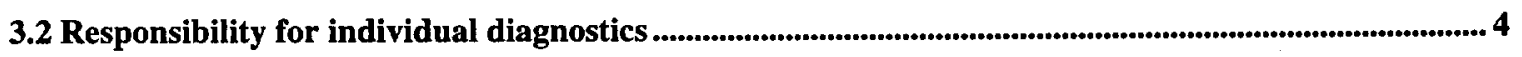

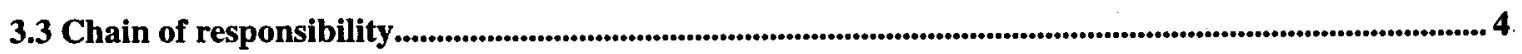

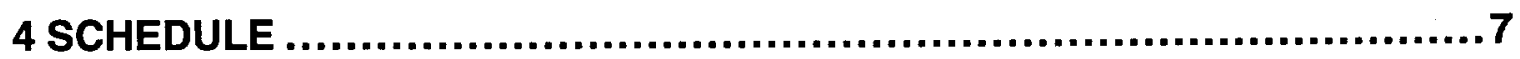

5 ANNUAL FUNDING AND RESOURCE REQUIREMENTS $\ldots \ldots \ldots \ldots \ldots \ldots \ldots \ldots . \ldots 7$

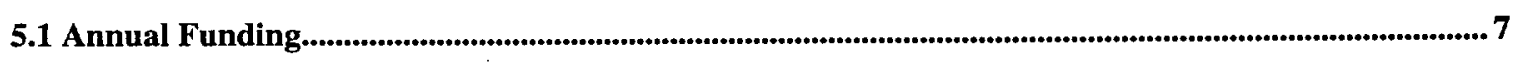

5.2 Documentation of resource requirements................................................................................................... 7

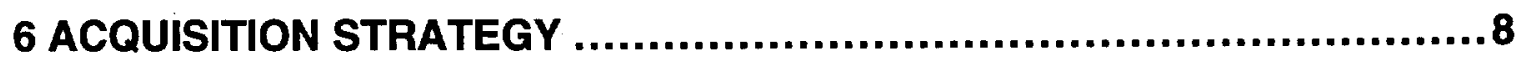

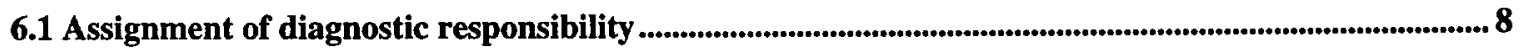

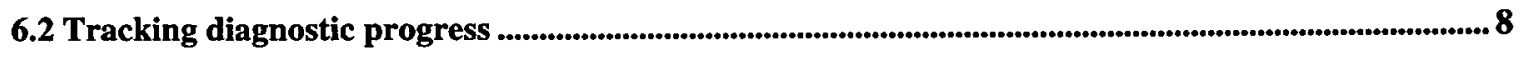

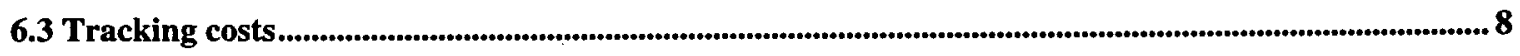

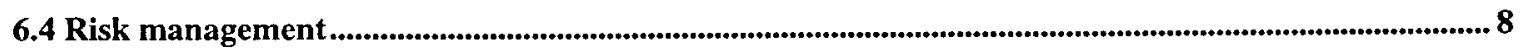

7 DEVELOPMENT/PROCUREMENT STRATEGY $\ldots \ldots \ldots \ldots \ldots \ldots \ldots \ldots \ldots \ldots . \ldots \ldots$

7.1 Primary Criteria and Functional Requirements. ......................................................................................................8

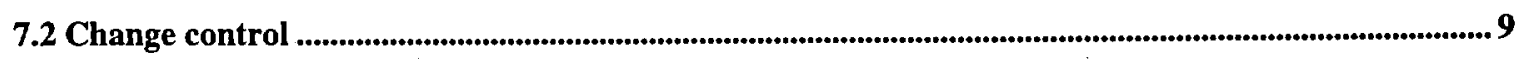

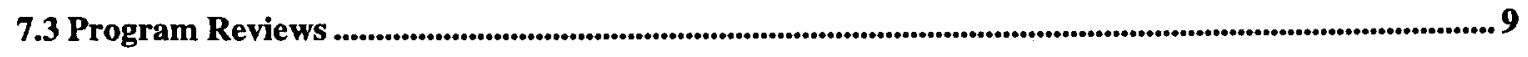

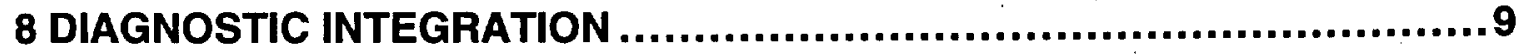




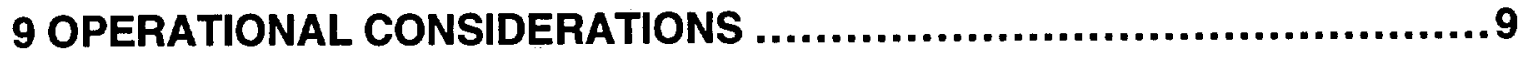

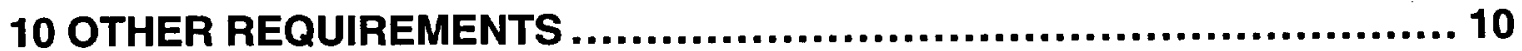

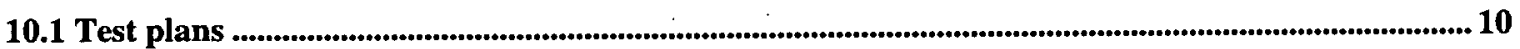

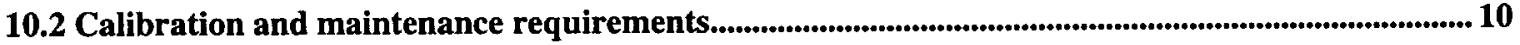

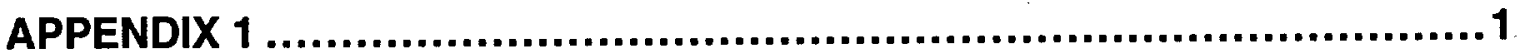




\title{
Interim Management Plan for the National NIF Diagnostics Program
}

\author{
April 10, 2002
}

\section{Introduction}

The National Ignition Facility (NIF) has the mission of supporting Stockpile Stewardship and Basic Science research in high-energy-density plasmas. To execute those missions, the facility must provide diagnostic instrumentation capable of observing and resolving in time events and radiation emissions characteristic of the plasmas of interest. The diagnostic instrumentation must conform to high standards of operability and reliability within the NIF environment. These exacting standards, together with the facility mission of supporting a diverse user base, has led to the need for a central organization charged with delivering diagnostic capability to the NIF. The National NIF Diagnostics Program (NNDP) has been set up under the aegis of the NIF Director to provide that organization authority and accountability to the wide user community for NIF. The funds necessary to perform the work of developing diagnostics for NIF will be allocated from the National NIF Diagnostics Program to the participating laboratories and organizations. The participating laboratories and organizations will design, build, and commission the diagnostics for NIF.

Restricted availability of funding has had an adverse impact, unforeseen at the time of the original decision to projectize NIF Core Diagnostics Systems and Cryogenic Target Handling Systems, on the planning and initiation of these efforts. The purpose of this document is to provide an interim project management plan describing the organizational structure and management processes currently in place for NIF Core Diagnostics Systems. Preparation of a Program Execution Plan for NIF Core Diagnostics Systems has been initiated and a current draft is provided as Attachment 1 to this document.

The National NIF Diagnostics Program Interim Management Plan provides a summary of primary design criteria and functional requirements, current organizational structure, tracking and reporting procedures, and current planning estimates of project scope, cost, and schedule. The NIF Director controls the NNDP Interim Management Plan.

A Draft Program Execution Plan (PEP) for the National NIF Diagnostics Program has been also been prepared (NIF-0072083, Oct 2001, attached as Attachment 1) that describes the NNDP technical, cost, and schedule baselines, the method by which the NNDP will fund and monitor the work to be done by the participating laboratories; the process for controlling changes; and the associated reporting and review process. This plan is expected to be approved by the relevant stakeholders at the appropriate time; however, since October 2001, the NNDP has been operating according to the processes laid out in the draft PEP. Below is a summary of the most important aspects of the NNDP that are being applied during this interim period before approval of the full PEP. 


\section{Program Scope}

\subsection{Current scope}

The current scope of the NNDP is described in detail in Attachment 1, the NNDP PEP. The scope of the Program is a set of diagnostics that are considered "Facility" diagnostics that will be funded through the NIF Director and owned and operated by the facility, available for all users. The initial set of diagnostics to be built by the NNDP is known as the "core" set of diagnostics. A table summarizing the current scope of the NNDP is included as Appendix 1 of this document.

The associated schedule of delivery of the diagnostics to NIF will be determined by available funding. A baseline budget and associated schedule is presented in the draft PEP, however current (FY02 and FY03 projected) shortfalls in funding will force prioritization and delay of some measurement capabilities.

\subsection{Criteria for selection of diagnostics as part of scope of NNDP}

The initial set of facility diagnostics and the initial work scope for the National NIF Diagnostic Program has been defined as the "core" set of diagnostics for NIF. "Core" diagnostics are defined as meeting all of the following criteria:

- Diagnostics that can be built with existing technology or relatively simple extrapolations to meet NIF requirements.

- Diagnostics that are of broad application to many different users.

- Diagnostics whose operation is part of the work scope of the National Ignition Facility.

The list of core diagnostics in Table 1 has been developed over the past several years in consultation with the NIF user community as represented by the Joint Committee on Diagnostic Technology (JCDT). The list has been distributed within the user community and discussed widely, including at Campaign 10 Program Managers meetings. The NIF Programs Review Committee also reviewed the set of core diagnostics in April 2001, and a recommendation was made to proceed with implementing the plan for developing and fielding the core set of diagnostics. Future reviews will be carried out by the Experiments Planning Advisory Committee (EPAC) that is part of the NIF governance process.

It is expected that the scope of the NNDP will be extended in the future. Diagnostics that do not presently meet the criteria for core diagnostics may later be elevated to that status. For example, diagnostics that are presently of interest only to a small minority of users or diagnostics that require demonstration of enabling technology could be added to the Program scope by the NIF Director, as advised by the EPAC, and included in the budget in subsequent submissions to NNSA.

\section{Management Organization}

\subsection{Overview of organization}

A single Program Manager based at the NIF site and reporting to the NIF Director leads the National NIF Diagnostics Program. 
The Program has three main organizational components:

1. A small management group based at the NIF site headed by the National NIF Diagnostics Program Manager and appointed by the NIF Director. Its role is coordination and management of scope, schedule, and budget baselines, controlling proposed changes to that baseline, and setting and maintaining standards and guidelines for diagnostics together with configuration management for diagnostics and their support systems.

2. Advisory boards and expert working groups consisting of scientists and engineers representing the various National Laboratories, NIF user groups, and areas of diagnostic expertise (JCDT).

3. Groups of scientists and engineers based at various laboratories, organizations and vendors who develop and bring diagnostics to the facility as funded by the Diagnostics Program.

\subsection{Responsibility for individual diagnostics}

Each diagnostic is treated as a separate project element within the NNDP with a single participating laboratory Control Account Plan (CAP) manager/lead engineer responsible for execution of the development, procurement, and integration of that diagnostic. Where multiple copies or modifications to a type of instrument are required, the same CAP manager/lead engineer is responsible. There may be cases in which a diagnostic may be separated into subsystems for which different leads will be responsible. The CAP manager/lead engineer may also delegate design decision authority for some aspects of the design or procurement to subcontractors.

\subsection{Chain of responsibility}

The chain of responsibility is summarized in the figure below; reporting is up the vertical line. NNSA will approve NNDP Primary Criteria and Functional Requirements as well as changes to these. NNSA, the NIF Director, and the NNDP Manager will establish and enforce an appropriate change control system for NIF Core Diagnostics Systems covering project scope, cost, and schedule. 


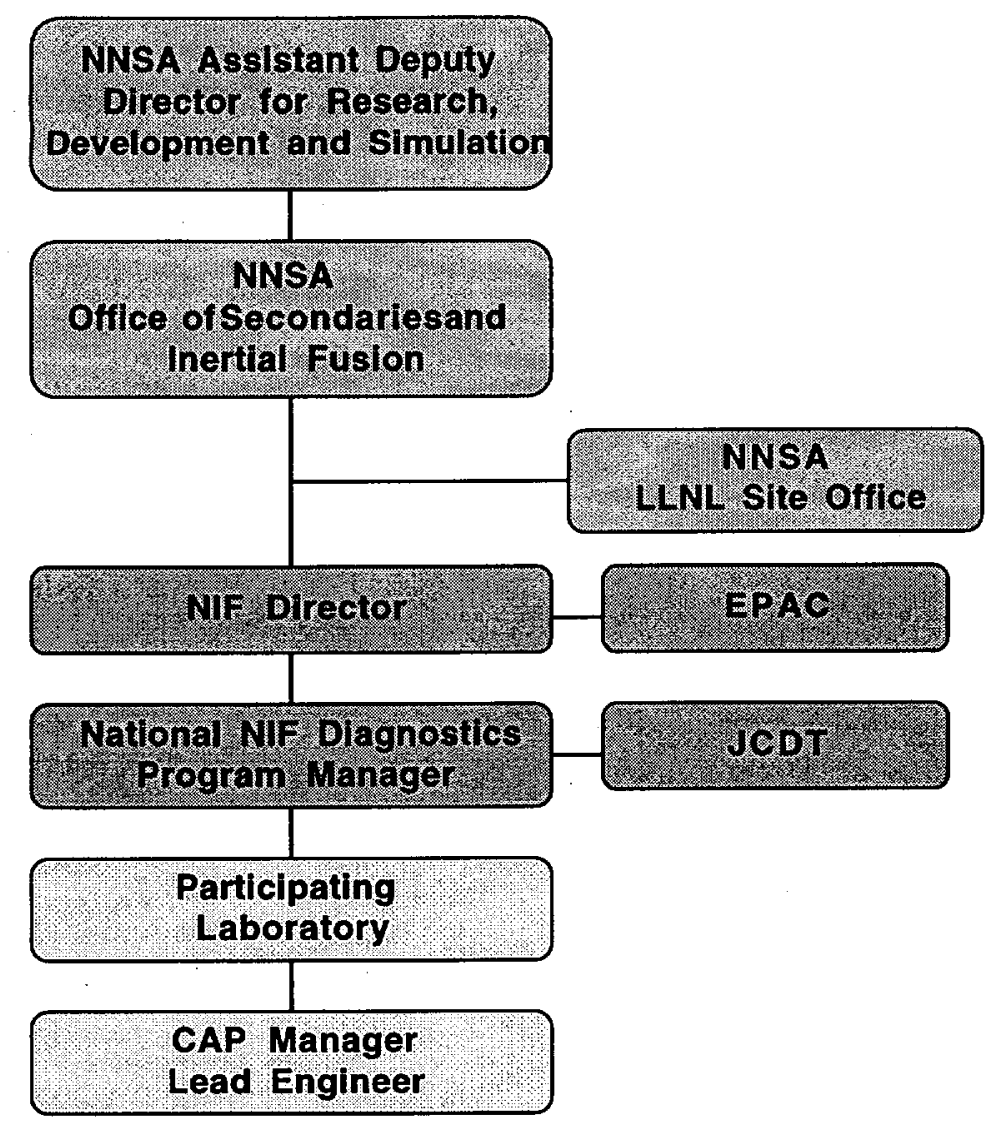

Figure 1. Management structure for the National NIF Diagnostics Program.

\subsubsection{NNSA Headquarters and LLNL Site Office}

The Director of the Office of Secondaries and Inertial Fusion at NNSA has programmatic responsibility for the science on NIF and for determining policy for reconciling programmatic goals and resource availability. The Director of the Office of Secondaries and Inertial Fusion exercises NNSA budgetary and programmatic oversight for all highenergy-density physics (HEDP) programs and projects outside the purview of the NIF Project Office, including facility diagnostics. The NNSA LLNL Site Office has the responsibility for managing the LLNL site activities. The Deputy Director, Office of the NIF Project, located at the LLNL Site Office, is the Federal Field Manager for ICF- and NIF-related activities, including the core diagnostics for NIF, and is responsible for implementing changes in the allocations to the participating laboratories based on input from the NIF Director, including issuance of Work Authorization Statements (WASs).

\subsubsection{NIF Director}

The NIF Director is responsible for developing and operating the NIF as a National Facility. The NIF Director works with NNSA to establish funding for diagnostics reviews on the progress of the NNDP and maintains a change control board. The NIF Director receives advice and recommendations from the Experiments Planning Advisory Committee representing the interests of the user communities of NIF. The NIF Director reports quarterly to NNSA on budget, schedule progress, and technical issues. 


\subsubsection{NNDP Manager}

The National NIF Diagnostics Program Manager is responsible for funding and delivery of the facility diagnostics on a schedule that is consistent with user needs and available resources. The NNDP Manager works with the participating laboratories to define scopes of work and appropriate funding plans to effect that delivery. Once work plans (known as CAPs) are agreed upon, the NNDP Manager periodically reviews progress through the reporting process from the participating laboratories and makes adjustments to plans as needed. The NNDP Manager maintains a staff of integration engineers to facilitate incorporation of diagnostics into NIF and maintain configuration control of standards and guidance documents. The NNDP Manager approves all design reviews and requirements documentation, maintains a Change Control Board to review changes to CAPs and requirements, and retains an advisory board (JCDT) representing the NIF user community and areas of diagnostic expertise. The NNDP Manager reports quarterly to the NIF Director and the NNSA Site Office on budget, schedule progress, and technical issues for diagnostics that are funded.

\subsubsection{Participating Laboratory Management}

A Memorandum of Understanding (MOU) between the partnering laboratory management and the NNDP describes the commitment on the part of the participating laboratory to deliver a diagnostic that meets the requirements for NIF on budget and on schedule. Terms for reporting to NNDP on the progress for a particular diagnostic are also included in the MOU. The participating laboratory management agrees to report on actual cost expenditure versus plan, projected expenditure, schedule status, technical status, and issues of concern. The participating laboratory assigns a CAP Manager and Lead Engineer together with appropriate staffing to complete the development and delivery of a diagnostic. Laboratory management will usually delegate the responsibility for reporting to the CAP Manager or CAP manager/lead engineer.

\subsubsection{CAP Manager/Lead engineer}

The CAP managers/lead engineers are responsible for producing a diagnostic for NIF in accordance with the design specifications and delivery schedule approved by the NNDP Manager. In the case where some aspect of the design or procurement has been delegated to another organization, the CAP manager/lead engineer remains responsible for ensuring that the diagnostic as a whole meets it technical goals. The CAP manager/lead engineer is part of the line management structure of the partnering laboratory or organization. As such, the CAP manager/lead engineer reports to the partnering institution's management according to their business practices. The CAP manager/lead engineer's responsibility derives from the commitment of the partnering laboratory management to deliver the diagnostic for use on NIF. The CAP manager/lead engineer is expected to interact closely with the NNDP Manager and the NNDP organization. Status and progress of NNDP efforts will be reported on a monthly basis to the NNDP Manager in accordance with CAP agreements.

The participating laboratory CAP manager is responsible for managing the resources to deliver the diagnostic according to the plan agreed upon with the NNDP. The CAP Man- 
ager may be the same person as the CAP manager/lead engineer or someone else appointed by the participating laboratory management.

\section{Schedule}

The current schedule of the NNDP is as described in the Draft PEP in Attachment 1. NIF will be determined by available funding.

However, shortfalls in funding will force prioritization and delay of some measurement capabilities, with schedule consequences to be determined as part of the overall HEDP Program rebaselining process currently in progress.

\section{Annual funding and resource requirements}

\subsection{Annual Funding}

The NNDP funding requests are made as part of the annual DOE/NNSA budget request process for inclusion in the NNSA Corporate Review Budget, the Office of Management and Budget, and the Congressional budget submissions. Overall NNDP funding budgets and associated scopes of work are negotiated and agreed to between the National NIF Director and NNSA NA-113.1. After agreement with NNSA NA-113.1, the NIF Director will establish annual budget guidance for the NNDP based on the negotiated scope of work and may request more detailed implementation plans for each Program participant from the NNDP Manager.

Approval authority for initial distribution and subsequent changes or adjustments to this distribution has been delegated to the NIF Project Deputy Director/Federal Field Manager. After Congressional authorization/appropriation of annual funding, NNSA will provide the NNDP funds to the appropriate Operations Offices via the approved financial plan process as requested by the NIF Director and authorized by the NIF Project Deputy Director/Federal Field Manager. The DOE Work Authorization System/Prime Contract Modification Process will be used by NNSA/DOE for the general authorization of funds for work at the participating laboratories and organizations. The individual WASs will be prepared and signed by NIF Project Deputy Director/Federal Field Manager, distributing NNDP funding according to the schedule provided by the NIF Director.

Specific authorization to begin work will be based on approval of the individual CAPs by the NNDP Manager as defined in the MOU between the Program and the participating laboratories and organizations. All subsequent changes to the CAPs will be via the change control process. Changes in funding will be effected by a transfer of funds from the LLNL Financial Plan to the Financial Plan of the affected participating Laboratory or Organization.

\subsection{Documentation of resource requirements}

The resource requirements for a particular diagnostic are documented in the CAP. The signed CAPs are maintained under change control in a controlled-access database. A limited management reserve is maintained by the NNDP Manager, allowing allocation of additional resources to diagnostics as necessary. Alternative options accessible through 
the change control board process to the NNDP Manager include adjusting schedule, modifying scope, or submitting a change request to a higher-level change control board.

\section{Acquisition Strategy}

\subsection{Assignment of diagnostic responsibility}

Responsibility for developing a diagnostic or part of a diagnostic and the associated resources to accomplish that task will be allocated to vendors/laboratories as recommended by the NNDP Manager and approved by the NIF Director. The determination will combine the interest of maintaining NIF as a national facility with involvement of as broad a range of participants as possible and with sound business practices for determining the most cost effective and reliable method of getting the work done.

\subsection{Tracking diagnostic progress}

Progress will be tracked by the NNDP Manager through a monthly reporting process together with acceptance by the NNDP Manager of design reviews and other test reports and other documentation that are part of the diagnostic development process. Each diagnostic will be tracked individually. Multiple copies or modifications to a particular diagnostic may be tracked as a group (e.g., low-cost spatial imaging snouts) or individually (e.g., the $5^{\text {th }}$ Diagnostic Instrument Manipulator) as appropriate.

The NIF Director will provide a quarterly report to the Director of the Secondaries and Inertial Fusion Division of the Office of Defense Science and the Deputy Director, Federal Field Manager, Office of the NIF Project, and the Director of Secondaries and Inertial Fusion.

\subsection{Tracking costs}

Costs will be monitored through the monthly reporting process as described elsewhere in this document. Summaries will be reported quarterly to the NIF Director and the NNSA Deputy Director, Federal Field Manager, Office of the NIF Project and the Director of Secondaries and Inertial Fusion..

\subsection{Risk management}

Risks and other issues will be identified to the NNDP Manager by CAP managers/lead engineers and documented through the monthly reporting process, and by the NIF Director to NNSA via the quarterly reporting process. Appropriate corrective action will be applied as necessary and will be implemented in an expedient manner through change control board action as necessary.

\section{Development/Procurement Strategy}

\subsection{Primary Criteria and Functional Requirements.}

The Primary Criteria and Functional Requirements (PC/FR) are based in part on the NIF Program PC/FR. The NNDP PC/FR is intended to be a repository for higher-level facility and diagnostics requirements from which aspects of individual diagnostics requirements 
will flow. The draft NNDP PC/FR were developed and reviewed by the user community through the JCDT and by members of the NIF Project, diagnostics engineers at LLNL, and at participating laboratories. It is expected that the EPAC will also review the NNDP $\mathrm{PC} / \mathrm{FR}$ and recommend approval or changes to the appropriate level change board.

\subsection{Change control}

Changes to the scope, schedule, or budget will be subject to the Change Control Board review process. Change Control Boards will be established for approval, disapproval, or endorsement of all proposed changes to the baseline. A documented change control process will be utilized for the NNDP.

\subsection{Program Reviews}

The requirements for the set of core diagnostics have undergone extensive peer review as described above. Most recently in April 2001, the NIF Programs Review Committee reviewed the detailed cost and schedule estimates. Future peer review of top-level requirements and implementation strategy will occur through annual reviews of diagnostic scope, schedule, and budget by the NIF EPAC. In addition, members of the user community with stakes in NIF diagnostics availability and performance will participate in diagnostic requirements and design review committees where issues such as technical risk and detailed requirements are continually monitored/evaluated.

The Director of the Office of Secondaries and Inertial Fusion will conduct reviews of overall project scope, schedule and cost for NNDP on an annual basis.

\section{Diagnostic Integration}

The NIF Programs Systems Engineering and Mission Support organization maintains integration engineers charged with facilitating the numerous interfaces between diagnostics and NIF. The NNDP will facilitate.CAP manager/lead engineer interactions with this organization and will maintain documentation summarizing the interfaces to diagnostic controls, timing, synchronization, alignment, vacuum, data acquisition, conventional facilities, and other systems. Understanding these interfaces and communicating guidelines for dealing with them is being undertaken incrementally with the most time urgent interfaces being dealt with first. Information on these interfaces is available in a controlled access database maintained by the NNDP for use by diagnostic teams.

For example, there is a standard defined for the communication protocol between diagnostic controllers and the NIF controls system that has been extensively reviewed by the JCDT, NIF controls personnel, and controls experts from the major laboratories. That standard (NNDP Diagnostic Communication Protocol for Target Diagnostic Controller Development, NIF-0051081, Jan 2002) is available in the controlled access database. Data archiving systems are also being developed and will be managed by the NNDP.

\section{Operational considerations}


The design review process for delivery and acceptance of a diagnostic to NIF includes the preparation of appropriate Environmental, Safety, and Health (ES\&H)-related documentation. He will include consideration of quality assurance requirements and plans. For work carried out at other partnering laboratory sites, the appropriate Integrated Safety Management (ISM) practices must be applied as described by the their policies and procedures. Prior to installation and acceptance at NIF, diagnostics must undergo a readiness review that serves as a Work Authorization Point (WAP). This readiness review will verify that appropriate safety and environmental assessments have been carried out prior to installation. A complete listing of the deliverables at the various design and readiness reviews is contained in the document, Design Review Process for Target Diagnostics on the National Ignition Facility, NIF-0074511-OB, December 2001. All review materials are available in the controlled access database.

\section{Other requirements}

\subsection{Test plans}

Test plans are deliverables of the design reviews listed in the Design Review Process for Target Diagnostics on the National Ignition Facility document. CAP managers/lead engineers must develop plans for off-line testing as well as tests during initial operation on NIF. The review team, with representation from the user community as well as the NIF facility, must approve these test plans.

\subsection{Calibration and maintenance requirements}

All diagnostics provided under the NNDP will have a technical plan for calibration and maintenance as part of the diagnostic deliverable. The technical plan for calibration will be consistent with the design envelope of that instrument. 


\section{Appendix 1}

Table 1. Core diagnostics for the NNDP.

\begin{tabular}{|c|c|c|c|c|}
\hline Basic Diagnostics & Acronym & $\begin{array}{l}\text { Number of } \\
\text { instruments }\end{array}$ & $\begin{array}{l}\text { Number of } \\
\text { locations }\end{array}$ & $\begin{array}{l}\text { First Articl } \\
\text { Available }\end{array}$ \\
\hline Diagnostic Instrument Manipulator(DiM) (6 ea) & DiM & 6 & 60 & Jul 03 \\
\hline Streaked X-ray Detector (SXD) (2 ea) & .YSXD & $3 \quad 2$ & DIM based & Van 03 \\
\hline Gated X-ray Detector (GXD) ( $4 \mathrm{ea})$. & GXO & 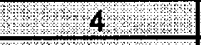 & DiMbased & Apr 04 \\
\hline Streaked Optical Detector(OSD) (multiple) & OSO & multiple & in opfical diags & as needed \\
\hline Static X-ray Imager(SX) $(2 \mathrm{ea})$, & SXI: & 2 & 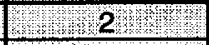 & $\operatorname{Jan} 03$ \\
\hline Optical Dlagnostics 4 Ch & Wutury & CuYuYu & DUU, & (U) \\
\hline Velocity Interferometer(VISAR)(3 locations) & VISAR & TBD & 3 & Jul-03 \\
\hline Passive Shock Breakout(PSBO) & PSBO & 1 & 1 & Jan-06 \\
\hline Full Aperture Backscatter(FABS) (2 ea) & FABS & 2 & 2 & Jul-03 \\
\hline Near Backscatter Imager(NBI) (2 ea) & $\mathrm{NBI}$ & 2 & 2 & Dec-05 \\
\hline 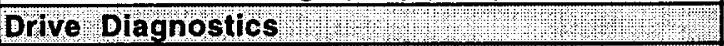 & W14t? & 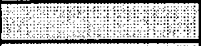 & 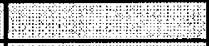 & 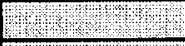 \\
\hline Soft X ray Power(Dante/DMX)(2 locations) & SWPD & 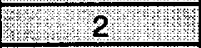 & 18: 2 & Wando6 \\
\hline Fard X ray Spectrometer ( $F$ FLEX X XRD) & WOD & 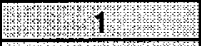 & 1010 1 & May 06 \\
\hline Snouts and spectroscopy & (3) & 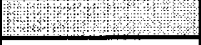 & 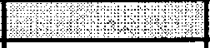 & 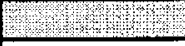 \\
\hline X-ray imaging snouts(HXRI) (multiple) & $\mathbf{H} \times \mathbf{R}$ & multiple & DIM-based & as needed \\
\hline Transmission grating snouts(ITGS) (multiple) & TIGS & multiple & DIM-based & as needed \\
\hline Soft x-ray imager(SXRI) & SXA & multiple & DIM-based & as needed \\
\hline X-ray spectroscopy snout(SPEC) (2 ea) & SPEC & multiple & DIM-based & Jul-05 \\
\hline Survey spectrometer(HENEX) & HENEX & 1 & DIM-based & Jul-04 \\
\hline Nuclear diagnostics & 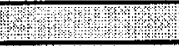 & 9PYY" & 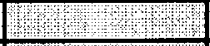 & \\
\hline Neutron Spectrometer(Tion) & Thion & 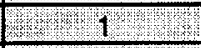 & 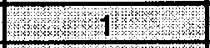 & Feb-06. \\
\hline Neutron Bang Time(bt) & BT & 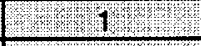 & TBB & Feb-06 \\
\hline Neutron time of filght(NTOF) & $\mathrm{NLOF}$ & 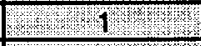 & TBD & May 07 \\
\hline Neutron Yleld (yn) ( 4 lines of sight) & $\mathrm{WN}$ & 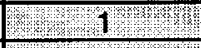 & 4 lines of sigh & May $=6$ \\
\hline Rad-Chem Debris diagriostic & DEBRIS & 1 & MTH & Wan 08 \\
\hline
\end{tabular}




\section{Attachment 1:}

Draft NNDP Program Execution Plan 